Original Research Paper

\title{
Using Crump Rubber (CR) of Scrap Tire in Hot Mix Asphalt Design
}

\author{
Omar Asad Ahmad \\ Department of Civil Engineering, Faculty of Engineering Technology, Zarqa University, Zarqa, Jordan
}

Article history

Received: 19-12-2015

Revised: 29-01-2017

Accepted: 07-02-2017

Email: support@thescipub.com

\begin{abstract}
Hot Mix Asphalt (HMA) design is one of the most important types of pavement used in highway construction. This research provided a hot mixture design method modifying with Crump Rubber Scrap Tire (CR) in order to develop and determining the optimum additive for hot mix asphalt design. All tests conducted to the raw material including specific gravity, compact test and absorption content to ensuring its quality. In this research, hot mix designed as a stander without any additives and with (4.5, $5,5.5,6,6.5$ and $7 \%$ ) percent of asphalt content. All specimens of each asphalt percent content were tested after $24 \mathrm{~h}$, according to AASHTO. The additives in this research were prepared by two methods (wet process and dry process). The results show that in dry process all additives cause a failure and the segregation was the major reason for failure. In wet process the selected wet process at $5.5 \%$ CR by weight of binder content was optimum were its raising the stability value to $65 \%$ of original stability in standard mix, which lead to decreasing the rutting effects.
\end{abstract}

Keywords: Rubber, Design, Modifier, Hot Asphalt, Stability, Flow

\section{Introduction}

Asphalt pavements are designed to resist rutting, fatigue cracking, low temperature cracking and other pavement distresses. Rutting and fatigue cracking are very known to be the most common distresses that occur in asphalt pavement. The rutting deformation occurs at high temperature and fatigue cracking which occurs at intermediate and low temperatures. These stresses reduce the design life of the pavement and increase the maintenance costs. This is due to the rapid growth of traffic volume and vehicle loads which led to unsatisfactory performance of asphalt binders (Cooley Jr et al., 2003). To minimize the structural damage of asphalt pavement and increase the durability of the pavement, the asphalt binder needs to be improved with regards to performance properties such as resistance against rutting and fatigue cracking (Cooley Jr et al., 2003; Martin et al., 2003).

Asphalt as a binder of aggregate has been widely used in road pavement. High-temperature cause rutting and low-temperature cause cracking of asphalt cement or coating layer due to the severe temperature and shortens its functional life. Therefore it is necessary to modify asphalt mix. Among the modifiers of asphalt, is Crumb Rubber (CR). The application of CRM asphalt is investigated by several researchers in the United States, Canada and other countries (Cheng, 2001; Magdy, 1997).

The previous research and application showed that CRM asphalt had many desirable effects such as improved resistance to rutting due to higher viscosity, higher softening point and better resilience, reduced fatigue/reflection cracking, reduced temperature susceptibility, improved durability and lower pavement maintenance costs. Another advantage for using CR is the reduction in waste by 7 recycling of waste tires and rubber which can have high cost to dispose of properly (Cheng, 2001). CR is the second used polymer to modify asphalt, following SBS (Yetkin, 2007).

The use of CRM asphalt is environmental friendly solution, since the use of this material partially reduces the need for new raw materials and improves the performances and life cycle of asphalt pavements (Miriam, 2009; Choubane et al., 1999). Several researchers studied the CRM asphalt. It is found that the improvement of CRM asphalt depended on many factors such as the particle size, the surface characteristics of $\mathrm{CR}$, blending conditions, the manner in which $\mathrm{CR}$ devulcanizes, the chemical/physical properties of base asphalt, as well as its source and microstructure (Yetkin, 2007; Bahia and Davies, 1994; Navarro et al., 2004; Lee et al., 2008; Cao and Chen, 2008; Shi et al., 2005; 
Xiang et al., 2009; González et al., 2012). Thodesena et al. (2009) developed an empirical model depicting the changes in values of $\mathrm{G}^{*} / / \sin \delta$ and failure temperatures. Liu et al. (2009) evaluated the performance of different modified binders with different CR contents, the particle size or type by using the analysis of variance method.

The crumb rubber is often sieved and separated in categories based on gradation to meet the requirements of a particular application or agency. Typically there are three classes of CR, mb rubber market, there are three main classes based on particle size: Grade A: 10 mesh coarse crumb rubber; Grade B: 14 to 20 mesh crumb rubber; Grade C: 30 mesh crumb rubber. Mesh size designation indicates the first sieve with an upper range specification between 5 and $10 \%$ of material retained.

Asphalt binder is the principal binding agent in Hot Mix Asphalt (HMA) and surface preservation treatments for flexible pavements such as fog seal, chip seal and crack sealing. Asphalt binder includes asphalt cement and any material added to modify the original asphalt cement properties. Some asphalt binders need modification to meet specifications. Modifiers can change the properties of the binder by: Lowering the viscosity at the construction temperature to facilitate pumping, mixing and compaction of HMA; increasing the viscosity at high service temperatures to reduce rutting and shoving; Increasing relaxation properties at low service temperatures to reduce thermal cracking; increasing adhesion between asphalt binder and aggregates in the presence of moisture to reduce or prevent stripping.

Crumb rubber can be used as an asphalt binder modifier to produce CRM modified Hot Mix Asphalt (HMA) concrete. HMA can be used in several pavement surface preservation or rehabilitation treatments, such as rubberized fog seal and rubberized chip seal.

Because of the complex nature of the rubber materials, their effect on the properties of the various types of asphalt binder and the HMA concrete mixtures are not always easy to predict without testing the modified binder (Roberts et al., 1996).

\section{Materials and Methods}

Crumb rubber was obtained from recycled tires. Crumb or ground rubber can be used either as fine aggregate in the mixture or as processed rubber added to the asphalt binder. To implement these two approaches, the dry process and wet process of using crumb rubber were developed.

The dry process is a method where granulated or Crumb Rubber Modifier (CRM) are added from scrap tires as a substitute for a percentage of the aggregate in the asphalt concrete mixture, not as part of the asphalt binder. The crumb rubber is mixed with the aggregate fraction before adding the asphalt cement. The resulting mix is often called rubber-modified asphalt concrete mixture. Different gradations or sizes of granulated or CRM can be used depending on the application or procedure. The percentage of the crumb rubber added in the dry process varies; Roberts et al. (1996) indicated that 3 to $5 \%$ of crumb rubber by weight of the aggregate is generally used (Navarro et al., 2004). The Asphalt Rubber Usage Guide refers to 1 to $3 \%$ of crumb rubber by weight of the aggregate in the asphalt concrete mixture (Roberts et al., 1996; Holikatti et al., 2012).

The wet process is a method of adding the asphalt binder with CRM from scrap tires before the binder is added to form the asphalt concrete mixture, the resulting product is called asphalt rubber or rubberized asphalt. The wet process requires thorough mixing of the CRM with the asphalt concrete and other components of the modified asphalt binder at temperatures between (190 to $224^{\circ} \mathrm{C}$ ) and requires maintaining the blend at temperatures between $\left(190\right.$ to $\left.218^{\circ} \mathrm{C}\right)$ for a certain specified time, generally 45 min (Caltrans, 2006).

\section{Laboratory Testing}

The following tests were conducted.

\section{Impact Test}

Impact test designed to evaluate the toughness of stones i.e., the resistance of the fracture under repeated impacts may be called an impact test for road stones. The test sample consists of aggregates passing $12.5 \mathrm{~mm}$ sieve and retained on $10 \mathrm{~mm}$ sieve and dried in an oven for four hours at a temperature 1000 to $1100^{\circ} \mathrm{C}$ and cooled. Test aggregates are filled up to about one-third full in the cylindrical measure and tamped 25 times with rounded end of the tamping rod. An aggregate is then added up to two-third full in the cylinder and 25 strokes of the tamping rod are given. The measure is now filled with the aggregates to over flow, tamped 25 times. The surplus aggregates are stroked using the tamping rod as straight edge. The net weight of the aggregates in the measure is determined to the nearest gram and this weight of the aggregates is used. The hammer is raised to a distance of $380 \mathrm{~mm}$ from the lower face and allowed to fall freely on the aggregates. The test sample is subjected to a total of 15 blows, each being delivered at an interval of not less than one second. The crushed aggregate were then removed from the cup and the whole sample is sieved on the $2.36 \mathrm{~mm}$ sieve until all fine size passes. The fraction passing the sieve is weighed to the nearest $0.1 \mathrm{gm}$. The fraction retained on the sieve is also weighed and if the total weight of the fractions passing and retained on the sieve is added. The specific gravity and absorption for coarse aggregate and sand are listed in Table 1. 
Table 1. Specific gravity and absorption for coarse aggregate and sand

\begin{tabular}{llll}
\hline Type & G APP & G bulk & Absorption\% \\
\hline $19-12.5 \mathrm{~mm}$ & 2.78 & 2.65 & 1.81 \\
$9.5-4.75 \mathrm{~mm}$ & 2.73 & 2.64 & 1.24 \\
$2.63-0.085 \mathrm{~mm}$ & 2.65 & 2.55 & 1.48 \\
Sand & 2.64 & 2.53 & 1.65 \\
\hline
\end{tabular}

\section{Penetration Test (AC 80/100)}

The penetration test: Is most commonly-used tests on asphalt cements or residues from distillation of asphalt cutbacks or emulsions. It is an empirical test which measures the consistency (hardness) of asphalt at a specified test condition. In the standard test condition, a standard needle of a total load of $100 \mathrm{~g}$ is applied to the surface of an asphalt sample at a temperature of $25^{\circ} \mathrm{C}$ for $5 \mathrm{sec}$.

\section{Ductility Test (106 mm)}

Ductility Test: Test goal is to completely melt the bituminous material to be tested by heating it to a temperature of 75 to $100^{\circ} \mathrm{C}$ above the approximate softening point until it becomes thoroughly fluid. Assemble the mould on a brass plate and in order to prevent the material under test from sticking, thoroughly coat the surface of the plate and the interior surfaces of the sides of the mould with a mixture of equal parts of glycerin. While filling, pour the material in a thin stream back and forth from end to end of the mould until it is more than level full. Leave it to cool at room temperature for 30 to $40 \mathrm{~min}$ and then place it in a water bath maintained at the specified temperature for $30 \mathrm{~min}$, after which cut off the excess bitumen using a hot, straight-edged putty knife or spatula, so that the mould is just level full. Place the brass plate and mould with briquette specimen in the water bath and keep it at the specified temperature for about 85 to $95 \mathrm{~min}$. Then, briquette was removed from the plate; detached the side pieces and the briquette immediately (Bressette et al., 2007).

\section{Softening Point Test}

Ring and Ball Softening Point Test: The ring and ball softening point test measures the temperature at which asphalt reaches a certain softness. The test is conducted by using Ring and Ball apparatus. A brass ring containing test sample of bitumen is suspended in liquid like water or glycerin at a given temperature. A steel ball is placed Upon the bitumen sample and the liquid medium is heated at a rate of $5^{\circ} \mathrm{C}$ per min. Temperature is noted when the softened bitumen touches the metal plate which is at a spaced distance below. Generally, higher softening point indicates lower temperature susceptibility and is preferred in hot climates.

\section{Marshall Test}

The Marshall Stability and flow test provides the performance prediction measure for the Marshall Mix design method. The test measures the maximum load supported by the test sample at a loading rate of 50.8 $\mathrm{mm} / \mathrm{min}$ called (stability test). Load is applied to the sample until failure stage. During the loading, an attached dial gauge measures the specimen's plastic flow (deformation) as a result of the loading. The flow value is recorded in $0.25 \mathrm{~mm}$, increments at the same time when the maximum load is recorded. The aggregate size distribution is shown in Tables 2 and 3.

Select $1200 \mathrm{gm}$ of aggregates. Then heated bitumen to a temperature of $125^{\circ} \mathrm{C}$ with the different percentage of bitumen (4.5-7\%) by weight of an aggregates. The mix is placed in a preheated mould and compacted by a hammer with 75 blows on both side at temperature of $145^{\circ} \mathrm{C}$. The weight of mixed aggregates taken for the preparation of the specimen may be suitably.

Stability and flow shown in Table 4 are the maximum load required to produce failure when the specimen is preheated to a prescribed temperature placed in a special test head and the load is applied at a constant strain. While the stability test is in progress dial gauge is used to measure the vertical deformation of the sample. The deformation at the failure point expressed in units of $0.25 \mathrm{~mm}$ is called the Marshall Flow value of the specimen. Properties of CR are discussed in Table 5.

The classification shown in Table 6 was used to select optimum binder content. So the optimum binder content is $5.5 \%$.

The binder is considered because it improves the major properties stability and flow. CR can be calculated as a fraction of aggregates or bitumen. However different ways can be utilized to calculate rubber fraction from total weight.

The research present two methods of CR addition, first method by fraction of weight of aggregates and the second method by replacing binder content $(5.5 \%$ in total mix) with different percentage of rubber.

Wet Process: Rubber is added to liquid asphalt before mixing at the hot plant, rubber is wet before mixing with aggregates. Dry Process: Rubber is added at the same time the asphalt and aggregate are mixed; rubber is dry before mixing with the aggregate.

Dry method was used for samples that have same weight of binder content with changing weight of aggregates replaced with the same size of rubber. For wet process the binder content is changed by weight by adding rubber weight of replaced aggregates. The rubber blending with bitumen first then aggregates added. Rubber is prepared to mixing in dry process by controlling its size to replace aggregates into two sizes by using sieves grader, because the size of pieces has not the same. The results are listed in Tables 7, 9, 12 and 15. 
Omar Asad Ahmad / American Journal of Applied Sciences 2017, 14 (2): 274.285 DOI: 10.3844/ajassp.2017.274.285

Table 2. Percentage of aggregate in used samples

\begin{tabular}{|c|c|c|c|c|}
\hline Sieve $(\mathrm{mm})$ & $\begin{array}{l}\text { Percent of aggregate } \\
\text { in sample } \%\end{array}$ & $\mathrm{~Gb}$ & Gapp & Average \\
\hline $25-12.5$ & 20 & 2.65 & 2.78 & 2.72 \\
\hline $9.5-4.75$ & 35 & 2.65 & 2.70 & 2.68 \\
\hline $2.36--0.85$ & 27 & 2.55 & 2.65 & 2.60 \\
\hline $0.5--0.075$ & 18 & 2.50 & 2.53 & 2.52 \\
\hline
\end{tabular}

Table 3. Percentage of aggregate and different bitumen of $1200 \mathrm{~g}$ total sample weight

\begin{tabular}{lcccccr}
\hline $\begin{array}{l}\text { Sieve } \\
(\mathrm{mm})\end{array}$ & $\begin{array}{l}\text { Accumulative } \\
\text { weight of } 4.5 \% \\
\text { blinder }\end{array}$ & $\begin{array}{l}\text { Accumulative } \\
\text { weight of } \mathbf{5 \%} \\
\text { blinder }\end{array}$ & $\begin{array}{l}\text { Accumulative } \\
\text { weight of } 5.5 \% \\
\text { blinder }\end{array}$ & $\begin{array}{l}\text { Accumulative } \\
\text { weight of } 6 \% \\
\text { blinder }\end{array}$ & $\begin{array}{l}\text { Accumulative } \\
\text { weight of } 6.5 \% \\
\text { blinder }\end{array}$ & $\begin{array}{l}\text { Accumulative } \\
\text { weight of } 7 \% \\
\text { blinder }\end{array}$ \\
\hline 25 & 0.00 & 0.0 & 0.00 & 0.00 & 0.00 & 0.00 \\
19 & 34.38 & 34.38 & 34.02 & 33.84 & 33.66 & 33.48 \\
12.5 & 229.20 & 228.0 & 226.80 & 225.60 & 224.40 & 223.20 \\
9.5 & 343.80 & 342.0 & 340.20 & 338.40 & 336.60 & 334.80 \\
4.75 & 630.30 & 627.0 & 623.70 & 620.40 & 617.10 & 613.80 \\
2.56 & 802.20 & 798.0 & 793.80 & 789.60 & 785.40 & 781.20 \\
0.85 & 939.72 & 934.8 & 929.88 & 924.96 & 920.04 & 915.12 \\
0.5 & 1031.40 & 1026.0 & 1020.60 & 1015.20 & 1009.80 & 1004.40 \\
0.15 & 1077.24 & 1071.6 & 1065.96 & 1060.32 & 1054.68 & 1049.04 \\
0.075 & 1111.62 & 1105.8 & 1099.98 & 1094.16 & 1088.34 & 1082.52 \\
Pan & 1146.00 & 1140.0 & 1134.00 & 1128.00 & 1122.00 & 1116.00 \\
\hline
\end{tabular}

Table 4. Stability and Flow results for different additives

\begin{tabular}{lllll}
\hline Sample & Wdry & Wssd-Wsub & Stability reading & Flow reading \\
\hline $4.5 \%$ & 1192 & 509.40 & 225 & 300 \\
$4.5 \%$ & 1189.4 & 510.50 & 240 & 340 \\
$5.0 \%$ & 1184 & 508.15 & 237 & 350 \\
$5.0 \%$ & 1187 & 507.26 & 269 & 400 \\
$5.5 \%$ & 1187.00 & 509.44 & 275 & 350 \\
$5.5 \%$ & 1188 & 512.06 & 251 & 450 \\
$6.0 \%$ & 1194 & 514.65 & 250 & 360 \\
$6.0 \%$ & 1194 & 512.49 & 293 & 500 \\
$6.5 \%$ & 1185 & 508.58 & 254 & 400 \\
$6.5 \%$ & 1188.00 & 512.07 & 299 & 500 \\
$7.0 \%$ & 1178 & 507.75 & 275 & 450 \\
$7.0 \%$ & 1180 & 508.65 & 250 & 500 \\
\hline
\end{tabular}

Table 5. Properties of samples with CR different additives

\begin{tabular}{|c|c|c|c|c|c|c|c|c|c|}
\hline Sample & $\begin{array}{l}\mathrm{Gb} \\
\mathrm{Mix}\end{array}$ & $\begin{array}{l}\text { Gapp } \\
\text { Mix }\end{array}$ & $\begin{array}{l}\mathrm{Gb} \\
\mathrm{agg}\end{array}$ & $\begin{array}{l}\text { Gapp } \\
\text { Agg }\end{array}$ & $\begin{array}{l}\text { AV } \\
\%\end{array}$ & $\begin{array}{l}\text { VMA } \\
\%\end{array}$ & $\begin{array}{l}\text { VFB } \\
\%\end{array}$ & $\begin{array}{l}\text { Stability } \\
\text { value }\end{array}$ & $\begin{array}{l}\text { Flow } \\
\text { reading }\end{array}$ \\
\hline $4.5 \%$ & 2.33 & 2.45 & 2.22 & 2.63 & 4.82 & 15.32 & 68.56 & 604.5 & 12.59 \\
\hline $5.0 \%$ & 2.33 & 2.43 & 2.21 & 2.63 & 4.10 & 15.77 & 74.01 & 657.8 & 14.76 \\
\hline $5.5 \%$ & 2.33 & 2.43 & 2.20 & 2.63 & 3.59 & 16.40 & 78.08 & 683.8 & 15.74 \\
\hline $6.0 \%$ & 2.33 & 2.40 & 2.18 & 2.63 & 3.00 & 16.95 & 82.26 & 705.9 & 16.92 \\
\hline $6.5 \%$ & 2.32 & 2.38 & 2.17 & 2.63 & 2.32 & 17.43 & 86.67 & 718.9 & 17.71 \\
\hline $7.0 \%$ & 2.32 & 2.36 & 2.15 & 2.63 & 1.70 & 17.99 & 90.52 & 682.5 & 18.70 \\
\hline
\end{tabular}

Table 6. Results of 5.5\% CR additives

\begin{tabular}{lll}
\hline Stability Kg & 683.8 & Pass \\
\hline Flow $0.25 \mathrm{~mm}$ & 15.74 & Pass \\
VMA\% & 16.40 & Pass \\
VFB\% & 78.08 & Pass \\
AV\% & 3.590 & Pass \\
\hline
\end{tabular}


Omar Asad Ahmad / American Journal of Applied Sciences 2017, 14 (2): 274.285 DOI: $10.3844 /$ ajassp.2017.274.285

Table 7. Percentage of CR replacement of aggregate

\begin{tabular}{|c|c|c|c|}
\hline Sieve mm & $\begin{array}{l}\text { Return weight of } 5.5 \% \\
\text { bitumen and } 25 \%(4.75) \text { rubber }\end{array}$ & $\begin{array}{l}\text { Return weight of } 5.5 \% \\
\text { bitumen and } 35 \%(4.75) \text { rubber }\end{array}$ & $\begin{array}{l}\text { Accumulative weight of } 5.5 \% \\
\text { bitumen and } 50 \%(4.75) \text { rubber }\end{array}$ \\
\hline 25 & 0.000 & 0.000 & 0.00 \\
\hline 19 & 34.020 & 34.020 & 34.02 \\
\hline 12.5 & 192.780 & 192.780 & 192.78 \\
\hline 9.5 & 113.400 & 113.400 & 113.40 \\
\hline 4.75 aggregate & 212.625 & 184.275 & 141.75 \\
\hline 4.75 rubber & 70.875 & 99.225 & 141.75 \\
\hline 2.36 & 170.100 & 170.100 & 170.10 \\
\hline 0.85 & 136.080 & 136.080 & 136.08 \\
\hline 0.50 & 90.720 & 90.720 & 90.72 \\
\hline 0.15 & 45.360 & 45.360 & 45.36 \\
\hline 0.075 & 34.020 & 34.020 & 34.02 \\
\hline pan & 34.020 & 34.020 & 34.02 \\
\hline
\end{tabular}

Table 8. Properties of samples with $5.5 \%$ bitumen and different CR

\begin{tabular}{lrrr}
\hline Sample & $25 \%$ & $35 \%$ & $50 \%$ \\
\hline Gb mix & 2.07 & 1.99 & 1.87 \\
Gapp mix & 2.43 & 2.43 & 2.43 \\
Gb agg & 1.95 & 1.88 & 1.76 \\
Gapp agg & 2.65 & 2.65 & 2.65 \\
AV \% & 14.80 & 18.10 & 23.00 \\
VMA \% & 26.20 & 29.00 & 33.30 \\
VFB \% & 43.40 & 37.70 & 30.90 \\
Stability value & 314.40 & 442.00 & 254.80 \\
Flow value & 28.00 & 38.00 & 39.00 \\
\hline
\end{tabular}

Second try $(9.5 \mathrm{~mm})$

Table 9. Percentage of $9.5 \mathrm{~mm} \mathrm{CR}$ aggregate replacement

\begin{tabular}{|c|c|c|c|}
\hline Sieve mm & $\begin{array}{l}\text { Return weight of } 5.5 \% \\
\text { bitumen } 25 \%(9.5) \text { rubber }\end{array}$ & $\begin{array}{l}\text { Return weight of } 5.5 \% \\
\text { bitumen } 35 \%(9.5) \text { rubber }\end{array}$ & $\begin{array}{l}\text { Accumulative weight of } 5.5 \% \\
\text { bitumen } 50 \%(9.5) \text { rubber }\end{array}$ \\
\hline 25 & 0.00 & 0.00 & 0.00 \\
\hline 19 & 34.02 & 34.02 & 34.02 \\
\hline 12.5 & 192.78 & 192.78 & 192.78 \\
\hline 9.5 aggregate & 85.05 & 73.71 & 56.70 \\
\hline 9.5 rubber & 28.35 & 39.69 & 56.70 \\
\hline 4.75 & 283.50 & 283.50 & 283.50 \\
\hline 2.36 & 170.10 & 170.10 & 170.10 \\
\hline 0.85 & 136.08 & 136.08 & 136.08 \\
\hline 0.50 & 90.72 & 90.72 & 90.72 \\
\hline 0.15 & 45.36 & 45.36 & 45.36 \\
\hline 0.075 & 34.02 & 34.02 & 34.02 \\
\hline Pan & 34.02 & 34.02 & 34.02 \\
\hline
\end{tabular}

Table 10. Properties of samples with $5.5 \%$ bitumen and different CR $9.5 \mathrm{~mm}$

\begin{tabular}{lcrr}
\hline Sample & $25 \%$ & $35 \%$ & $50 \%$ \\
\hline Gb mix & 2.22 & 2.21 & 2.10 \\
Gapp mix & 2.43 & 2.43 & 2.43 \\
Gb agg & 2.10 & 2.10 & 2.00 \\
Gapp agg & 2.65 & 2.65 & 2.65 \\
AV \% & 8.6 & 9.00 & 13.50 \\
VMA \% & 20.9 & 21.10 & 25.10 \\
VFB \% & 58.5 & 57.60 & 46.10 \\
Stability Value & 494.0 & 421.00 & 551.20 \\
Flow value & 20.00 & 21.00 & 24.00 \\
\hline
\end{tabular}


Omar Asad Ahmad / American Journal of Applied Sciences 2017, 14 (2): 274.285

DOI: 10.3844/ajassp.2017.274.285

Table 11. Results of $9.5 \mathrm{~mm}$ CR modifying samples Modify sample

\begin{tabular}{|c|c|c|c|c|c|}
\hline Properties & $25 \%$ & $35 \%$ & $50 \%$ & Standard sample & Result \\
\hline$\% \mathrm{AV}$ & 8.6 & 9.0 & 13.5 & 3.59 & Reject \\
\hline$\%$ VMA & 20.9 & 21.1 & 25.1 & 16.40 & Reject \\
\hline$\% \mathrm{VFB}$ & 58.5 & 57.6 & 46.1 & 78.08 & Reject \\
\hline Stability & 494.0 & 421.0 & 551.2 & 683.08 & Reject \\
\hline Flow & 20.0 & 21.0 & 24.0 & 15.74 & Reject \\
\hline
\end{tabular}

Table 12. Percentage of $9.5 \mathrm{~mm}$ and $4.75 \mathrm{~mm}$ CR aggregates replacement

\begin{tabular}{lccc}
\hline Sieve $\mathrm{mm}$ & $\begin{array}{l}\text { Return weight of 5.5\% } \\
\text { bitumen } 25 \%(4.5-9.5) \text { rubber }\end{array}$ & $\begin{array}{l}\text { Return weight of } 5.5 \% \\
\text { bitumen } 35 \%(4.75-9.5) \text { rubber }\end{array}$ & $\begin{array}{l}\text { Accumulative weight of } 5.5 \% \\
\text { bitumen } 50 \%(4.75-9.5) \text { rubber }\end{array}$ \\
\hline 25 & 0.000 & 0.000 & 0.00 \\
19 & 34.020 & 34.020 & 34.02 \\
12.5 & 192.780 & 192.780 & 192.78 \\
9.5 aggregate & 85.050 & 73.710 & 56.70 \\
9.5 rubber & 28.350 & 39.690 & 56.70 \\
4.75 aggregate & 212.625 & 184.275 & 141.75 \\
4.75 rubber & 70.875 & 99.225 & 141.75 \\
2.36 & 170.100 & 170.100 & 170.10 \\
0.85 & 136.080 & 136.080 & 136.08 \\
0.50 & 90.720 & 90.720 & 90.72 \\
0.15 & 45.360 & 45.360 & 45.36 \\
0.075 & 34.020 & 34.020 & 34.02 \\
Pan & 34.020 & 34.020 & 34.02 \\
\hline
\end{tabular}

Table 13. Properties of samples with 5.5\% bitumen and different CR 9.5 and $4.75 \mathrm{~mm}$

\begin{tabular}{lrrr}
\hline Sample & $25 \%$ & $35 \%$ & $50 \%$ \\
\hline Gb mix & 2.02 & 1.85 & 1.74 \\
Gapp mix & 2.43 & 2.43 & 2.43 \\
Gb agg & 1.91 & 1.75 & 1.64 \\
Gapp agg & 2.65 & 2.65 & 2.65 \\
AV \% & 16.90 & 23.70 & 28.40 \\
VMA \% & 21.40 & 27.90 & 32.40 \\
VFB \% & 21.30 & 15.10 & 12.20 \\
Stability Value & 543.40 & 286.00 & 247.00 \\
Flow value & 31.00 & 33.00 & 43.00 \\
\hline
\end{tabular}

Table 14. Results of 9.5 and $4.75 \mathrm{~mm}$ CR modifying samples

\begin{tabular}{|c|c|c|c|c|c|}
\hline \multirow[b]{2}{*}{ Properties } & \multicolumn{3}{|c|}{ Modify sample } & \multirow[b]{2}{*}{ Standard sample } & \multirow[b]{2}{*}{ Result } \\
\hline & $25 \%$ & $35 \%$ & $50 \%$ & & \\
\hline$\% \mathrm{AV}$ & 16.9 & 23.7 & 28.4 & 3.59 & Reject \\
\hline$\% \mathrm{VMA}$ & 21.4 & 27.9 & 32.4 & 16.40 & Reject \\
\hline$\% \mathrm{VFB}$ & 21.3 & 15.1 & 12.2 & 78.08 & Reject \\
\hline Stability & 543.4 & 286.0 & 247.0 & 683.08 & Reject \\
\hline Flow & 31.0 & 33.0 & 43.0 & 15.74 & Reject \\
\hline
\end{tabular}

Table 15. Results of CR weight for different additives

\begin{tabular}{lll}
\hline Percent of rubber & Binder weight & Rubber weight \\
\hline $3.5 \%$ & $63.69 \mathrm{~g}$ & $2.31 \mathrm{~g}$ \\
$4.5 \%$ & $63.03 \mathrm{~g}$ & $2.97 \mathrm{~g}$ \\
$5.5 \%$ & $62.37 \mathrm{~g}$ & $3.63 \mathrm{~g}$ \\
$6.5 \%$ & $61.71 \mathrm{~g}$ & $4.29 \mathrm{~g}$ \\
$7.5 \%$ & $61.05 \mathrm{~g}$ & $4.95 \mathrm{~g}$ \\
\hline
\end{tabular}

Most of rubber size was (4.75 and $9.5 \mathrm{~mm})$, so we select this size to testing in same processor of standard mix design by adding percentage $(25,35$ and $50 \%$ ) by weight of aggregates $4.75 \mathrm{~mm},(25,35$ and $50 \%)$ by weight of aggregates $9.5 \mathrm{~mm}$ and $(25,35$ and $50 \%$ ) of both 4.75 and $9.5 \mathrm{~mm}$ aggregates size. The properties of sample such as (stability, flow, voids filled with bitumen and air voids), Must be improved and any losses in quality in standard mix after adding rubber leading to reject the method, where the results reported in Tables 8, 10, 11, 13 and 14 . 


\section{Results and Discussion}

The aim of this research is to improve the major properties of Asphalt mix including stability and flow by selecting $5.5 \%$ of binder content and different rubber percentages. However, adding rubber was calculated by two methods, by total weight, replaced fillers aggregate with rubber and by replacing bitumen percentage with rubber percentage. In Table 9, the addition method involve adding different percent by weight of aggregates and by replacing fixed percentages of binder content (5.5\% in total mix) with different percentage of rubber. First test $(4.75 \mathrm{~mm})$ : In this test the selected percentage was removed from aggregates and replaced with rubber at same percent as removed.

In wet process method $\mathrm{CR}$ is added to liquid asphalt at temperatures around 110 to $155^{\circ} \mathrm{C}$ and we select small percent to adding (3.5, 4.5, 5.5, 6.5 and 7.5\%). Only, small fraction additions are used since large percentage may cause segregation.

The addition method is by substituting the selected percent of rubber from optimum binder content as standard mix (5.5\%). This percent equal $66 \mathrm{~g}$ which should be removed to add $3.5 \%$ and the weight removed was $2.31 \mathrm{~g}$. However; this rubber quantity is added to liquid and it is completely mixed and fully suspended.

To prepare the samples same way in the standard method, rubber was cut to small size to make it easier to melt. The mix has $1134 \mathrm{gm}$ of aggregates and 66 gm of bitumen in standard mix, Table 15 describe the weight of bitumen and rubber to add for fixed weight of aggregates.
Tables 15 and 16 summarize laboratory test results for all rubber percentages. Tables 15 and 16 shows acceptable values (except $3.5 \%$ failure in air voids percent). The percentage falls within general classification when the air void has a range between 3 and $5 \%$ maximum and the percent of void of mineral aggregates not less than $15 \%$. Then we observed that voids filled with bitumen specified between 75 and $85 \%$. Generally, the stability and flow was within general classification when stability was not less than $600 \mathrm{~kg}$ for wearing layer at heavy traffic and the flow was between $8 \%$ and $16 \%$ maximum. This classification is not considered in our study for wet process, because standard mix is selected for reference and it show improved mix.

Bulk specific gravity is directly proportional with quantity of rubber and rubber size as shown in Fig. 1. This trend is caused by changes in volume liner relation with additional rubber, rubber has lower density than aggregates, so we need to increase quantity to gets the needed weight.

However, density of sample will decrease as rubber increase, for example if we have $1200 \mathrm{gm}$ at standard state and the volume is around $508 \mathrm{~cm}^{3}$ and the density calculated as dividing the weight by volume will be 2.36 $\mathrm{gm} / \mathrm{cm}^{3}$. At 4.75 maximum densities recorded 2.07 $\mathrm{g} / \mathrm{cm}^{3}$ comes from adding $70.875 \mathrm{gm}$ of rubber and 28.35 gm of 9.5. We observed that density go up to 2.22 at 9.5 $\mathrm{mm}$, because the quantity is small. The bulk specific gravity decrease and this trend are related to high quantity of CR added and a volume increase of $(56.7 \mathrm{~g})$ was reported. So when rubber added, the volume will increase and the density go smaller.

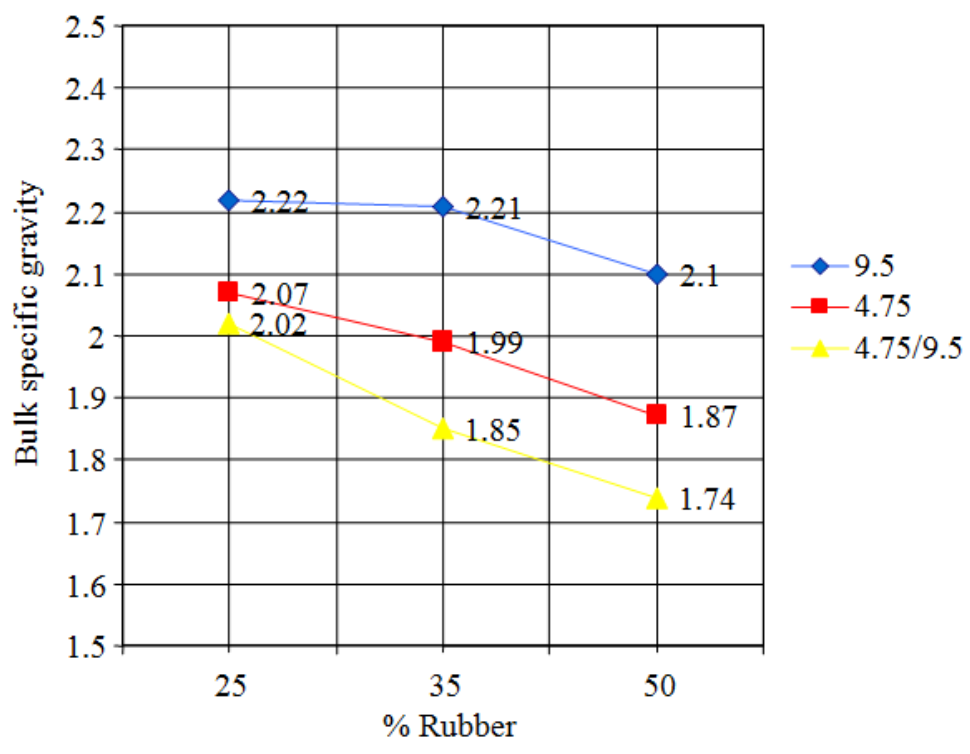

Fig. 1. Variations of bulk specific gravity with variety of $\% \mathrm{CR}$ 
For AV property, we observed a highest value for the mix contain both size of rubber (4.75 and 9.5) as shown in Fig. 2, because of non-equal distribution of temperature on all rubber pieces. So, some of the particles stay in solid state (at least in inner body). So when heating and mixing finished and compacted step is done. The rubber after cooling and decreasing pressure will solidify again. This behavior leads to changing in volume of rubber particle from large size to small size to make gaps between an aggregate. This is shown in $9.5 \mathrm{~mm}$ of rubber, because the quantity is less; the heating and mixing was more homogeneous, so the rubber transformed from solid stage to semi liquid state and this lead to distribution of all melting rubber around all aggregates and filling the small gabs. For 4.75 at $(25 \%)$ and that means increasing in $\mathrm{Gb}$ leads to decease the Air voids.

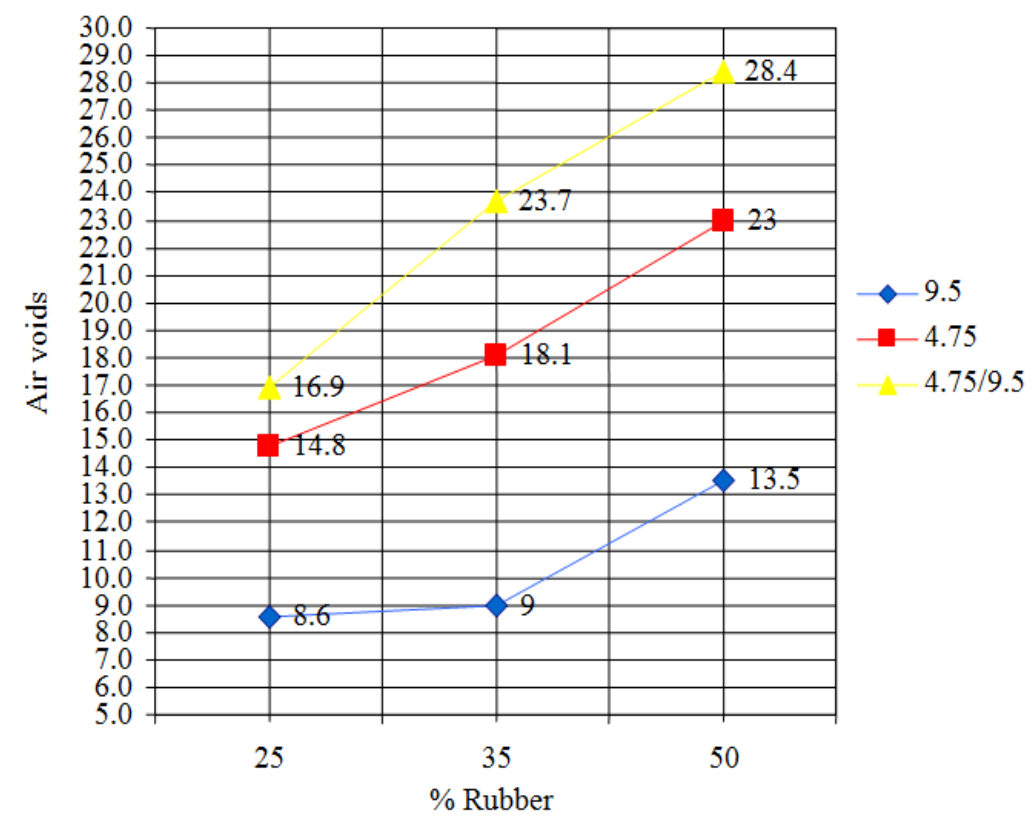

Fig. 2. AV changes in samples with variety of $\% \mathrm{CR}$

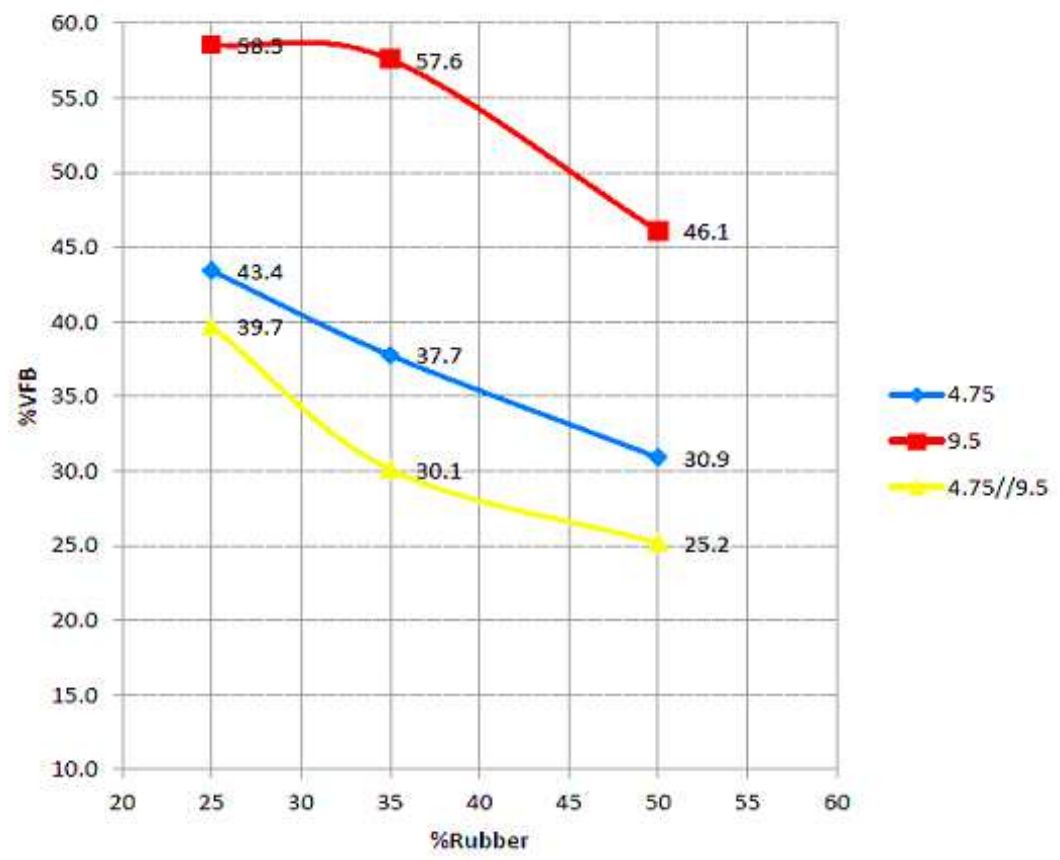

Fig. 3. VFB changes in samples with variety of $\% \mathrm{CR}$ 
VFB property changes when quantity of rubber is large as shown in Fig. 3, the voids filled with bitumen decrease, this can be referred to rubber has not fully melted and some parts remain in solid state. This is because rubber resists motion with bitumen. Finally liquid network (rubber plus bitumen) has high viscosity which would not fill all voids.

Flow properties show failure in stability as shown in Fig. 4 and Fig. 5 and this failure is caused by segregation in the sample, because the rubber when its added to the mix at large amount cause segregation between aggregates and bitumen. This is because rubber attach to aggregates when it's fully melted. If rubber is not fully melted it will not attach with bitumen.
Air voids increase linearly with rubber content as shown in Fig. 6 where more voids are added to bitumen which cause an increase in mixing liquid viscosity. But it is improving the mix by increasing this value from $3.59 \%$ in standard mix to 4.5 in the mix with rubber. However; the best value of air voids falls at $4 \%$ average of classification acting between ( 3 and $5 \%$ ) and it falls at this around $6.5 \%$ rubber with $4.3 \%$ air voids.

VFB curve decreases with increasing rubber content as shown in Fig. 7, but it is improving the percent of voids filled with liquid (bitumen and rubber); the standard mix have VFB of $78.08 \%$ as the rubber raise, also VFB increase to 81.12 at $3.5 \%$ rubber and VFB of 80.6 at $4.5 \%$ of rubber and VFB of 79 at $5.5 \%$ of rubber. So we improve this property without adding more asphalt.

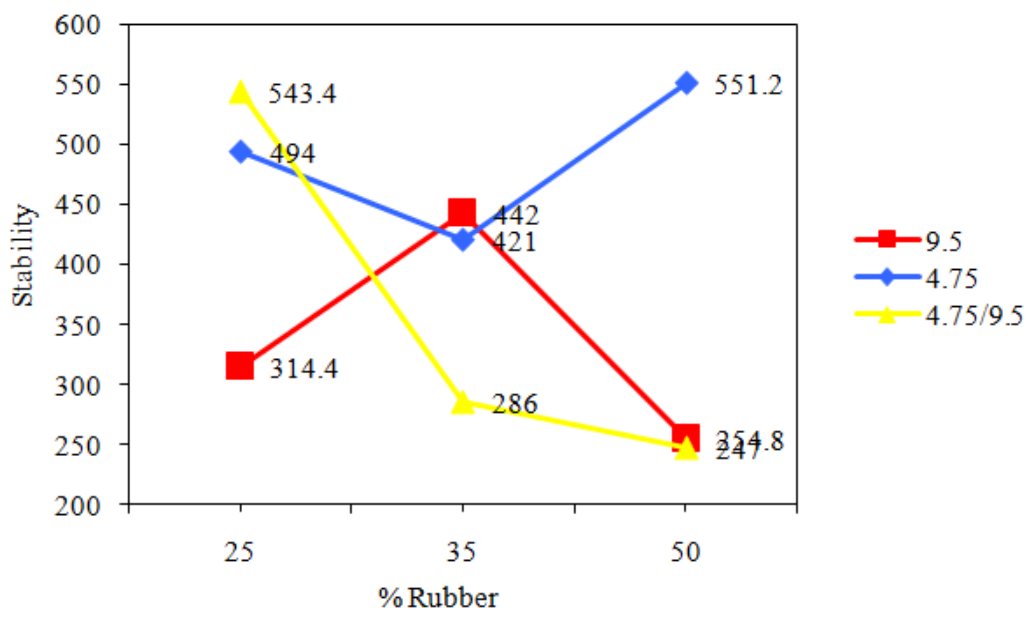

Fig. 4. Stability variations in samples with variety of $\% \mathrm{CR}$

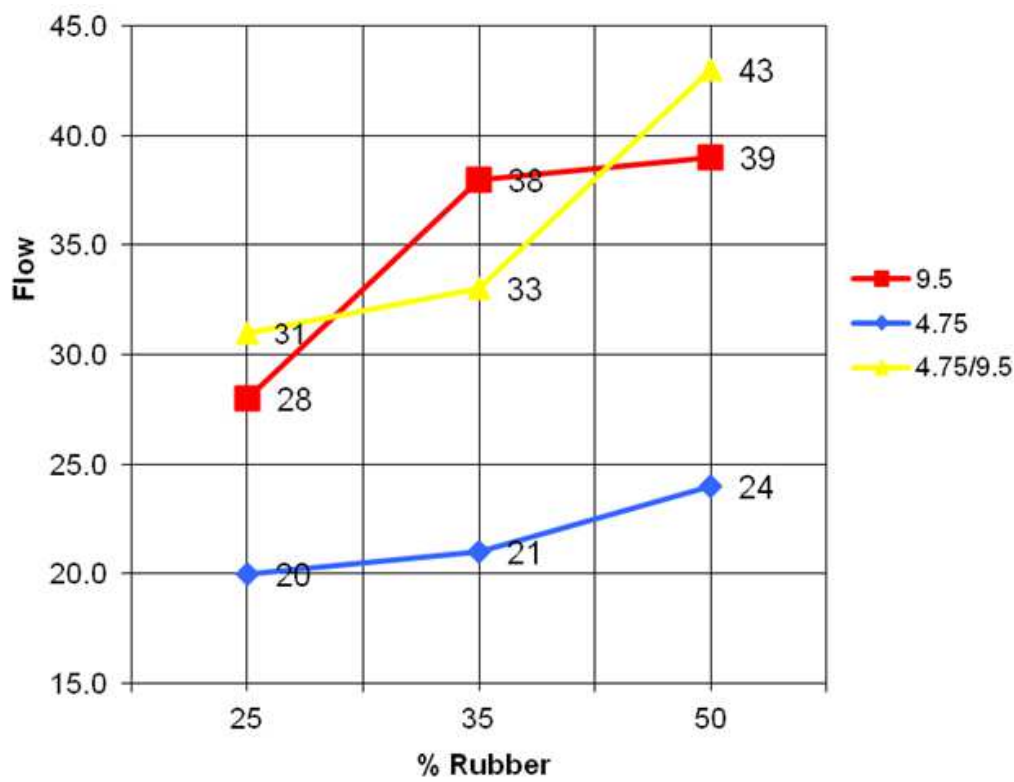

Fig. 5. Flow changes in samples with variety of $\% \mathrm{CR}$ 


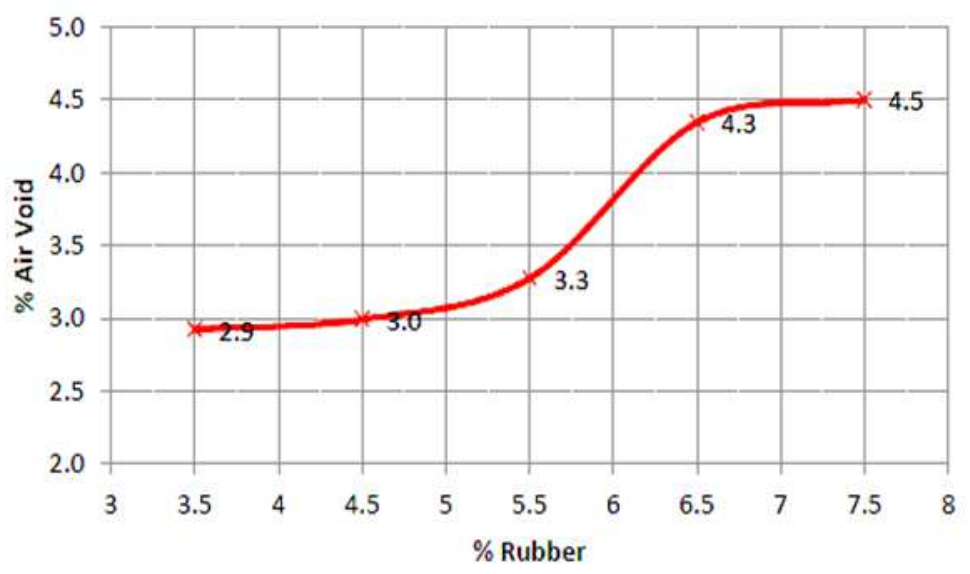

Fig. 6. Air Voids changes in samples with variety of $\% \mathrm{CR}$

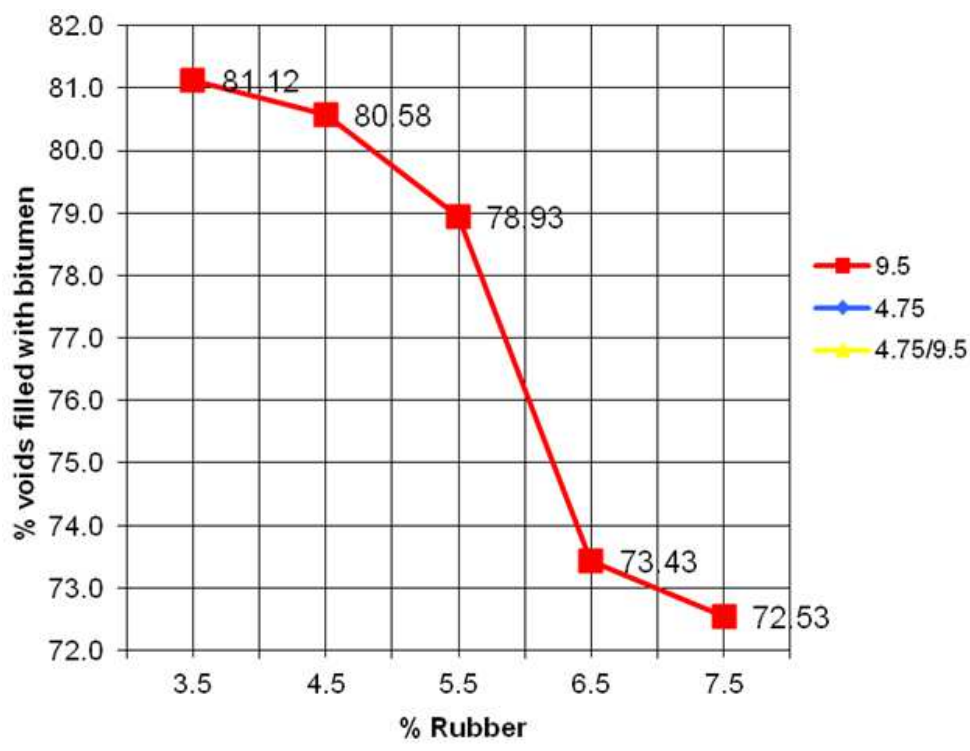

Fig. 7. Percentage of changes in voids with variety of $\% \mathrm{CR}$

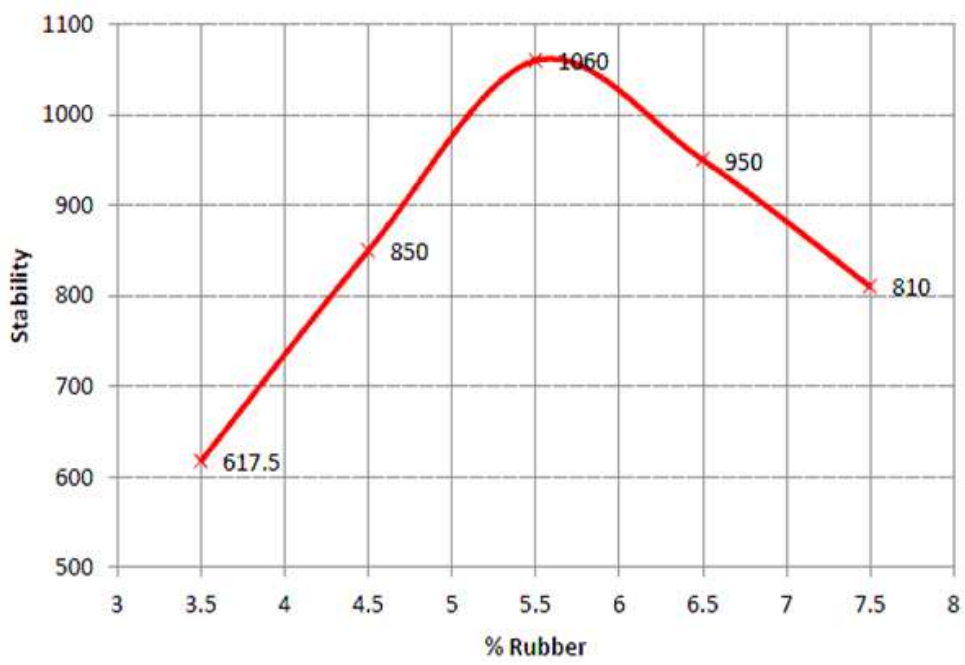

Fig. 8. Stability changes in samples with variety of $\% \mathrm{CR}$ 


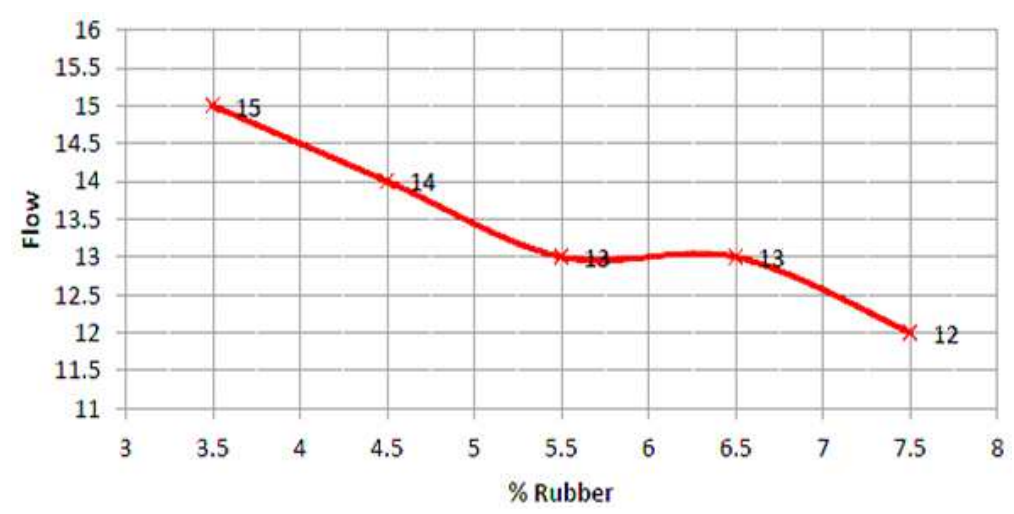

Fig. 9. Flow changes in samples with variety of $\% \mathrm{CR}$

Table 16. Results of stability and flow for $\% \mathrm{CR}$

\begin{tabular}{lllllrl}
\hline \%Rubber & Gb of mix & \% AV & \% VMA & \% VFB & Stability & Flow \\
\hline $3.5 \%$ & 2.365 & 2.9 & 15.48 & 81.12 & 617.5 & 15 \\
$4.5 \%$ & 2.366 & 3.0 & 15.41 & 80.58 & 850.0 & 14 \\
$5.5 \%$ & 2.361 & 3.3 & 15.55 & 78.93 & 1060.0 & 13 \\
$6.5 \%$ & 2.337 & 4.3 & 16.36 & 73.43 & 950.0 & 13 \\
$7.5 \%$ & 2.335 & 4.5 & 16.39 & 72.53 & 810.0 & 12 \\
\hline
\end{tabular}

Stability trend is shown in Fig. 8, it indicates an increase in stability such as at $5.5 \%$ of rubber has stability value $1065 \mathrm{~kg}$, when the value at standard mix was $683.08 \mathrm{~kg}$ a segregation in mix was observed. Stability increased incrementally up to $5.5 \%$ and is reduced after $5.5 \%$.

The value of flow decreased from 15.75 at standard mix to $12 \mathrm{~min}$ and this referred to extra rubber additives to bitumen that decreasing flow indexes in the mix as shown in Fig. 9.

\section{Conclusion}

Air voids in compacted paving mixture consist of the small air spaces between the coated aggregate particles. The small space allow moving a bitumen through as a loads (vehicle) moves on road. That mean, it's very important property in the mix, because if no air spaces in the mix the bitumen will moving to the lowest pressure point.

This point at a surface or nearly cracks acting in the pavement. This observation leads to bleeding in the bitumen on the surface. However; in wet process the best percentage at $5.5 \%$ rubber content equal $3.3 \%$. May we can select 4.3 at $6.5 \%$ rubber content, but it's nearest for limitation.

Voids filled with Bitumen in the compacted paving mixture consist of the bitumen content can fill large gap between aggregates. See at $4.5 \%$ rubber content the VFB was $80.6 \%$ with $63.03 \mathrm{~g}$ bitumen and for $6.5 \%$ rubber content the VFB was $73.4 \%$ with $61.7 \mathrm{~g}$ bitumen content. But at $5.5 \%$ rubber content, the VFB is around $79 \%$ more than $6.5 \%$ rubber content and low than $4.5 \%$ rubber content around 1\% VFB. At $62.3 \mathrm{~g}$ bitumen content, whilst the $4.5 \%$ rubber content with $63 \mathrm{~g}$.

Stability and flow tests indicate the ability of asphalt paving mixture to resist deformation due to loads, unstable pavement are marked by channeling or rutting. However; the recommendation is to select $5.5 \%$ rubber content of $1060 \mathrm{~kg}$. These means increasing of interlock between aggregates and resist the fraction.

\section{Acknowledgment}

This research is funded by the Deanship of Research and Graduate Studies in Zarqa University/Jordan-Zarqa.

\section{Ethics}

This article is original and contains unpublished material. The corresponding author confirms that all of the other authors have read and approved the manuscript and no ethical issues involved.

\section{References}

Bahia, H.U. and R.R. Davies, 1994. Effect of Crumb Rubber Modifiers (CRM) on performance related properties of asphalt binders. J. Assoc Asphalt Pav. Technol., 1: 414-420.

Caltrans, 2006. Use of rubberized asphalt concrete for new construction. Memorandum, Caltrans, Sacramento, CA.

Cao, R.J. and R.S. Chen, 2008. Laboratory study on process parameters of asphalt rubber and their effects on performance. J. Southeast Univ., 38: 269-273. 
Cheng, Y., 2001. Prospect for application of waster rubber powder. China Synthetic Rubber Ind., 24: 65-66.

Choubane, B., G.A. Sholar, J.A. Musselman and C.C. Page, 1999. Ten-year performance evaluation of asphaltrubber surface Mixes. Trans. Res. Rec., 1681: 1018. DOI: $10.3141 / 1681-02$

Cooley Jr, L.A., B.D. Prowell and M.R. Hainin, 2003. Comparison of the saturated surface-dry and vacuum sealing methods for determining the bulk specific gravity of compacted hma (with discussion and closure). J. Assoc. Asphalt Pav. Technol., 72: 56-96.

González, V., F. Martínez-Boza, C. Gallegos, A. Pérez-Lepe and A. Páez, 2012. A study into the processing of bitumen modified with tire crumb rubber and polymeric additives. J. Fuel Process. Technol., 95: 137-143. DOI: 10.1016/j.fuproc.2011.11.018

Holikatti, S., H. Zhou and P. Vacura, 2012. Seven year itch-evaluation of Caltrans full scale experiment on asphalt rubber modified pavements. Rubberized Asphalt Foundation.

Lee, S.J., C.K. Akisetty and S.N. Amirkhanian, 2008. The effect of Crumb Rubber Modifier (CRM) on the performance properties of rubberized binders in HMA pavements. Construct. Build. Mater., 22: 1368-1376. DOI: 10.1016/j.conbuildmat.2007.04.010

Liu, S.T., W.D. Cao, J.G. Fang and S.J. Shang, 2009. Variance analysis and performance evaluation of Different Crumb Rubber Modified (CRM) asphalt. Construct. Build. Mater., 23: 2701-2708. DOI: 10.1016/j.conbuildmat.2008.12.009

Magdy, A.A., 1997. Engineering characterization of the interaction of asphalt with crumb rubber modifier. J. Sci. Eng., 57: 51975179.

Martin, J., L.A. Cooley Jr. and H.R. Hainin, 2003. Production and construction issues for moisture sensitivity of hot-mix asphalt pavements. Proceeding of the Transportation Research Board National Seminar, Feb. 4-6, San Diego, California, pp: 209-222.
Miriam, E., 2009. Use of coupling agents to stabilize asphalt-rubber-gravel composite to improve its mechanical properties. J. Clean. Product., 17: 1359-1362. DOI: 10.1016/j.jclepro.2009.04.002

Navarro, F.J., P. Partal, F. Martinez and C. Gallegos, 2004. Thermo-rheological behaviour and storage stability of ground tire rubber-modified bitumens. Fuel, 83: 2041-2049. DOI: 10.1016/j.fuel.2004.04.003

Roberts, T.J., J.M. Weber, H. Hoppeler, E.R. Weibel and C.R. Taylor, 1996. Design of the oxygen and substrate pathways. II. Defining the upper limits of carbohydrate and fat oxidation. J. Exp. Biol., 199: 1651-1658. PMID: 8708572

Shi, H.B., M.X. Zou and K.J. Liao, 2005. Research progress of ground tire rubber modified pavement asphalts. J. Chem. Indus Eng., 26: 27-30.

Bressette, T., H. Zhou and A. Stonex, 2007. Asphalt rubber and its potential use in China. Proceedings of the 7th International Conference of Chinese Transportation Professionals, (CTP' 07), Shanghai.

Thodesena, C., K. Shatanawia, S. Amirkhaniana and W. Bridges, 2009. Development of an empirical model for determining $G^{*} / \sin \delta$ in crumb rubber modified binders. Construct. Build. Mater., 22: 1922-1927.

DOI: 10.1016/j.conbuildmat.2008.09.002

Xiang, L., J. Cheng and G.H. Que, 2009. Microstructure and performance of crumb rubber modified asphalt. Construct. Build. Mater., 23: 3586-3590. DOI: 10.1016/j.conbuildmat.2009.06.038

Yetkin, Y., 2007. Polymer modified asphalt binders. Construct. Build. Mater., 21: 66-72. DOI: 10.1016/j.conbuildmat.2005.07.007 